\title{
Cinema e Vídeo em Tempos de Pandemia: As mostras virtuais
}

\author{
Alexsandro de Sousa e Silva \\ Universidade do Estado de Minas Gerais (UEMG), Unidade Passos \\ alexsandro.silva@uemg.br \\ https://orcid.org/0000-0002-0897-565X
}

O ano de 2020 não marca apenas o início da crise pandêmica decorrente do vírus SARS-CoV-2, conhecido como Covid-19. Impulsiona também as formas virtuais de acesso e visualização de materiais audiovisuais, algo que já estava colocado com o desenvolvimento dos computadores. No entanto, o fechamento de salas de cinema, em razão das restrições sanitárias, e não apenas por sucessivas crises provocadas pelo acesso doméstico a filmes via VHS, DVD, Blu-ray e, ultimamente, por plataformas de streaming como a Netflix, parece reconfigurar as formas de distribuição, exibição e fruição. Nathan Nascimento Cirino e Kleyton Jorge Canuto enfatizam o caráter doméstico e isolado dessa cultura cinematográfica, que estava em ordenamento antes da pandemia (2021, 271-272). A reabertura do Cine Belas Artes e a estreia da longa Doutor Gama de Jeferson De (2021), em Belo Horizonte, Minas Gerais, a princípios de agosto, parece comprovar essa tendência, tendo em vista os escassos quatro espectadores/as adeptos/as da tela gigante, presentes na sessão. Há um longo trabalho a ser feito após o fim da pandemia: redescobrir e dar novos significados à tradicional forma de ver filmes.

Enquanto isso, curadoras/es utilizam as plataformas virtuais para seguir trazendo reflexões em som e imagens. Analisamos aqui duas mostras de filmes que destacam, entre outros temas, a história da luta social no Brasil, as religiões de matrizes africanas e indígenas e o racismo: o Festival Cine Terreiro - Filmes que ligam ao sagrado, cujos títulos estiveram acessíveis no mês de abril de 2021, e a mostra Joel Zito Araújo: uma década em vídeo, 1987-1997, disponível entre julho e 
agosto. Foram duas oportunidades, entre tantas (poderíamos também mencionar as duas edições do Cine África Online em 2020 e, da mesma equipe curadora, a Mostra de Cinemas Africanos em outubro 2021). Porém, muitos títulos das mostras selecionadas não circularam em festivais e, ao mesmo tempo, rememoram experiências inacessíveis (Mostra Joel Zito Araújo) e consolidam tendências cinematográficas contemporâneas (Festival Cine Terreiro).

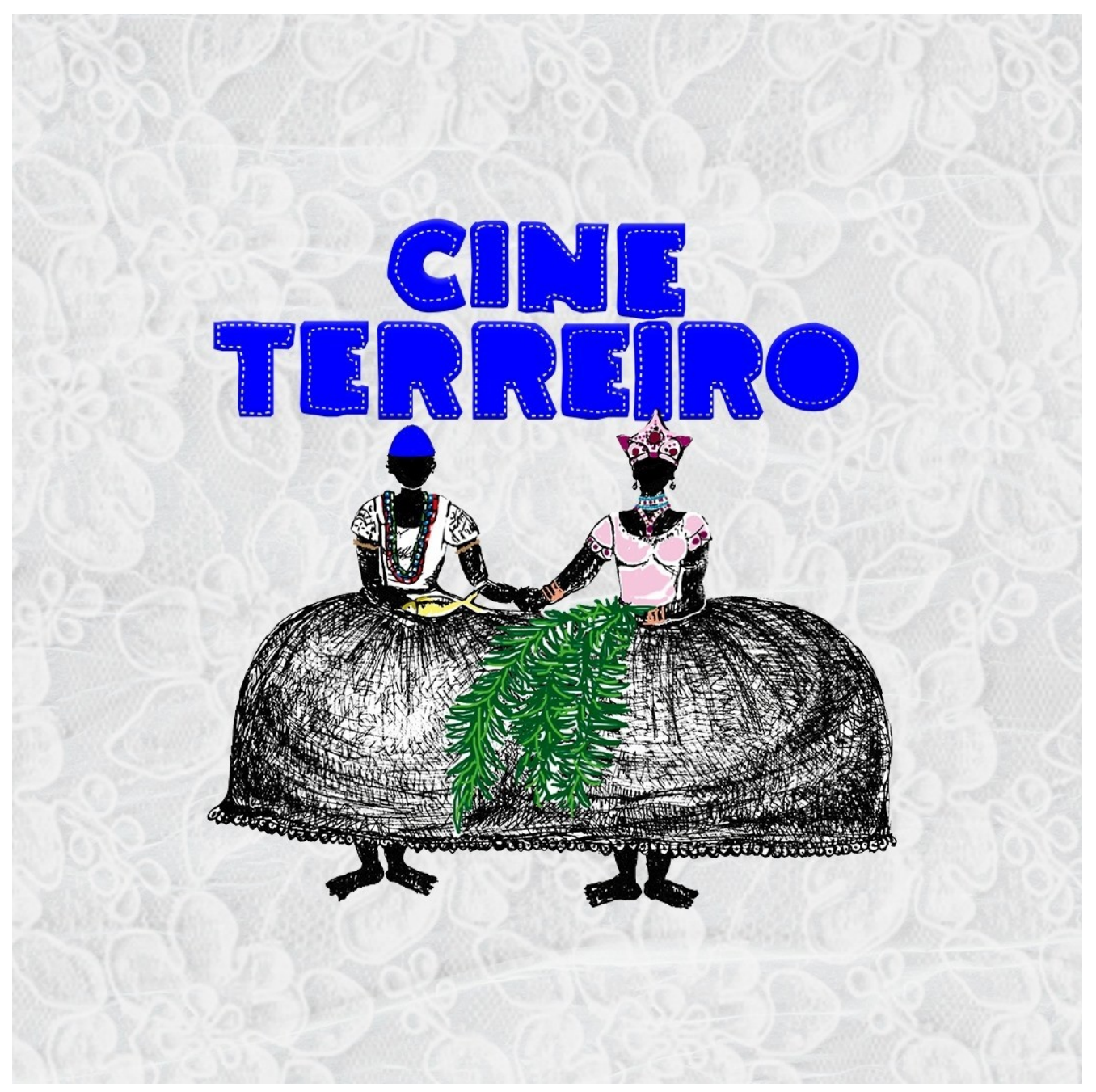

Imagem 1: Logotipo do Festival Cine Terreiro, 2021 | (c) Divulgação.

aniki Exposições e festivais de cinema | Exhibitions and film festivals 
O Festival Cine Terreiro - Filmes que ligam ao sagrado exibiu títulos sobre as correntes religiosas afro-indígenas e estruturou-se em três mostras (Mata, Grão e Mar). ${ }^{1}$ A possibilidade de haver eventos plurais como este explicita como um governo propenso a correntes neopentecostais, tal é o caso do governo brasileiro contemporâneo, não é monolítico, porque há batalhas internas nas instituições que produzem resultados interessantes. No espaço público, a perseguição contra terreiros sagrados intensificou-se ao longo da pandemia, seja por ação das forças de ordem pública do próprio Estado ao invadir terreiros (Marins e Peres 2021), seja pelo judiciário, quando separa mães praticantes do Candomblé e suas filhas sob acusações infundadas (Bassette 2020), seja por ação direta de grupos e indivíduos intolerantes à diversidade religiosa que destroem espaços e objetos sagrados (Miranda 2020). A organização defende "que formar um público interessado em assistir e discutir filmes sobre esses assuntos que envolvem mito, religiosidade e cultura de terreiros - pode contribuir para diminuição da segregação e preconceito contra esses grupos" (Sobre 2021). O evento, portanto, não tem um fim limitado ao campo cinematográfico, mas envolve também preocupações sociais mais amplas.

A mostra Mata trouxe cinco longas-metragens, com títulos como o paraibano O seu amor de volta (mesmo que ele não queira) (2018), de Bertrand Lira, sobre as práticas religiosas que envolvem os sentimentos íntimos; o elogiado Memórias Afro-Atlânticas (2019), de Gabriela Barreto, que retrata as pesquisas do estadunidense Lorenzo Dow Turner em terreiros de candomblé na Bahia entre 1940 e 1941; e As cores do divino (2020) de Victor Costa Lopes, sobre a diversidade sexual nos terreiros. A mostra Grão é composta por oito curtasmetragens, como Nigiro: meu nome, minha ancestralidade (2020), de Assaggi Piá, a respeito dos nomes de origem indígena e africana que passam a ser reivindicados; O atabaque na minha vida (2019), de Jéssica Martins, primeiro de uma série de seis episódios sobre a importância do instrumento nos terreiros com depoimentos de especialistas dentro e fora da academia; e o panorâmico Afro-amazônicos e seus símbolos

\footnotetext{
${ }^{1}$ O Festival foi organizado pela "produtora Ori Audiovisual e ABOCA Audiovisual, com patrocínio da OÑA, Lei Aldir Blanc, Fundação José Augusto, Governo do RN, Secretaria Especial de Cultura, Ministério do Turismo, Governo Federal, e apoio da Camará Filmes" (Sobre 2021). Acesso a 31 de outubro 2021. https://cineterreiro.com.br/sobre/
} 
(2016), de Tainah Jorge, do Pará, com os depoimentos de zeladores/as e pais/mães de santo sobre a importância da natureza nos terreiros.

Por fim, a mostra Mar exibiu oito curtas, entre eles a animação mineira Mãtãnãg, a encantada (2019), de Shawara Maxakali e Charles Bicalho, em idioma Maxakali; O jardim fantástico (2020), de Fábio Baldo e Tico Dias, narrativa de professora que usa Ayahuasca para conectar crianças a outra realidade; e o admirado Joãosinho da Goméa - O rei do candomblé (2020), de Janaina Oliveira Refem e Rodrigo Dutra, centrado na performance, como em outros títulos do festival, a respeito do babarolixá Joãosinho da Goméa. ${ }^{2}$ Além das mencionadas mostras, o evento estreou o curta Terreiro de Cinema (2021), de Rodrigo Sena, de Natal do Rio Grande do Norte, que mostrou a diversidade religiosa afro-indígena da cidade.

O festival expôs uma ampla cobertura geográfica do país e contemplou uma grande variedade de frentes religiosas e de existência. Além da exibição de filmes, decorreram oficinas (Ebó Ejé e Cinemando) e debates virtuais com realizadores. Os filmes passaram por um processo de premiação conforme as mostras Grão (sendo O atabaque da minha vida o título contemplado) e Mar (que premiou $O$ jardim fantástico). O evento foi uma importante porta de entrada no universo do sagrado a muitos cinéfilos/as, e mostra que possui grande potencial de avançar para novas edições, a fim de combater posicionamentos prejudiciais aos universos religiosos afro-indígenas dentro e fora do cinema.

\footnotetext{
${ }^{2}$ João Alves de Torres Filho (1914-1971), conhecido como Joãozinho da Gomeia, foi uma liderança religiosa em terreiros de Candomblé, nação Angola, de Salvador e Rio de Janeiro, com trajetória reconhecida socialmente.
} 


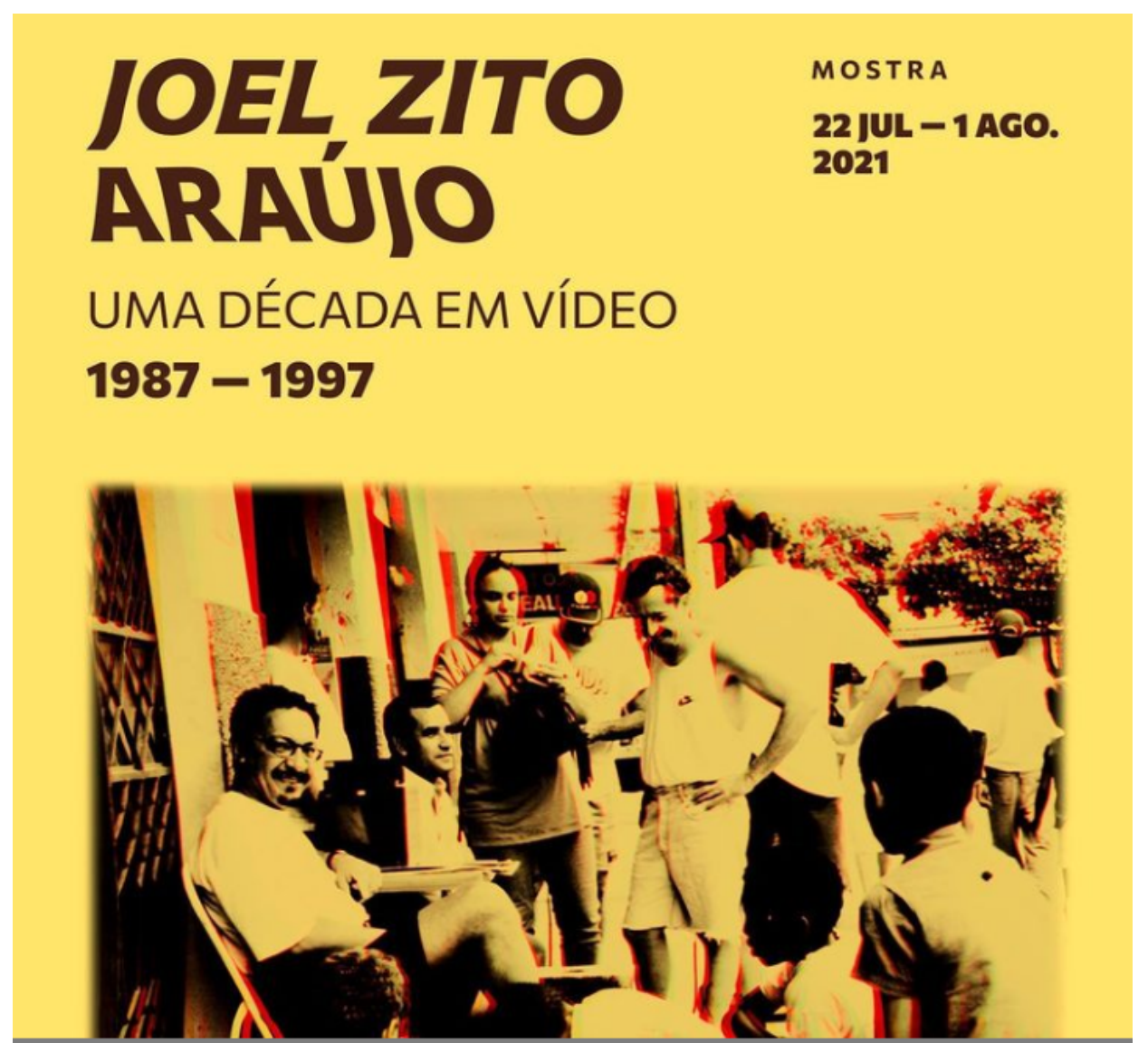

Imagem 2: Arte da Mostra Joel Zito Araújo | (c) Divulgação.

Por sua vez, a mostra Joel Zito Araújo: uma década em vídeo, 1987-1997 descortinou uma importante e desconhecida fase do cineasta, responsável por documentários como A negação do Brasil (2001), sobre a escassa presença negra na teledramaturgia brasileira; Cinderelas, lobos e um príncipe encantado (2009), que adentrou o difícil tema das relações inter-raciais entre mulheres negras do Brasil e cônjuges europeus; e o premiado Meu amigo Fela (2019), a respeito do cultuado músico nigeriano Fela Kuti. Na ficção, dirigiu As filhas do vento (2004) e, atualmente, está em processo de filmagem de $O$ pai da Rita. Com uma carreira respeitável no cinema, pouco se sabia de sua atuação no campo do vídeo, e a mostra ajuda a compreender uma trajetória marcada por leituras críticas sobre o racismo brasileiro e a disposição em escutar diferentes vozes alijadas das câmeras.

A produção contemplada na mostra abrange parcerias com movimentos sociais, sindicatos e organizações civis dos anos 1980 e 1990, fruto de pesquisas em acervos audiovisuais esparsos que 
reuniram grande parte do repertório videográfico do diretor. São filmes de memória, de ação social e antirracista. Um canal da mostra disponibiliza a visualização dos filmes e materiais extras, compondo um rico acervo das temáticas proletárias, sociais e raciais. ${ }^{3}$

Ainda que os primeiros filmes sejam marcadamente classistas e sindicalistas, sempre com a parceria do cineasta Renato Tapajós, a questão negra e feminina estava posta. Nossos bravos (1987) tem um operário negro (interpretado por Gésio Amadeu, recentemente falecido de complicações derivadas da Covid-19) ${ }^{4}$ que, numa roda de conversa sobre a história das greves no Brasil, recorda a exclusão negra durante a imigração europeia. Memórias de classe (1989) e Almerinda, uma mulher de trinta (1991) trazem a importante atuação sindical de Almerinda Farias Gama (1899-1999), mulher negra, com bonitas memórias e fotografias. São filmes ficcionais e documentários marcadamente didáticos, e nem por isso menos relevantes socialmente.

A grande contribuição da mostra é, sem sombra de dúvida, as obras que tratam abertamente do "racismo à brasileira". São Paulo abraça Mandela (1991), com cenas da visita do então líder sul-africano e Winnie Mandela à metrópole brasileira, com falas de Sueli Carneiro, da então prefeita Luiza Erundina, e outras lideranças e integrantes dos movimentos negros; Alma negra da cidade (1991), com depoimentos de artistas e anônimos; Homens de rua (1991), acerca do difícil tema da falta de moradia; Retrato em preto e branco (1992), uma desconstrução da ideia de "democracia racial"; Eu, mulher negra (1994), com Ruth de Souza, um verdadeiro manifesto pela saúde das mulheres negras; e o média-metragem A exceção e a regra (1997), sobre casos de racismo em Florianópolis e São Paulo no âmbito do emprego. Com este último título, o tema sindical retorna em favor de um dos discriminados e fecha o ciclo que entrelaça questões de classe e de raça.

Junto ao catálogo (Oliveira e Alves 2021), o material extra e as lives organizadas pelo evento, a mostra traz um panorama dos problemas sociais que a pandemia e governos pouco comprometidos com o combate à desigualdade social trazem de volta. No contexto brasileiro, os atuais índices de famílias na extrema pobreza, cerca de 2 milhões

\footnotetext{
${ }^{3}$ Mostra Joel Zito Araújo: uma década em vídeo, 1987-1997. Acesso a 31 de outubro, 2021. https://mostrajoelzitoaraujo.com.br/catalogo/.

${ }^{4}$ (Gshow. 2020).
} 
segundo reportagem recente (Madeiro 2021), remetem-se às imagens desumanas nos noticiários dos anos 1990. Assistir a filmes como Homens de rua é deparar-se com um espelho social incômodo, por meio de cenas que, acreditava-se, eram algo do passado, uma vez que os governos progressistas entre 2002 e 2016 empenharam-se, com relativo êxito, em reduzir a miséria. Com a crescente vulnerabilidade social, elevam-se também os casos de racismo, uma vez que a maioria da população pobre é, também, negra. Os movimentos sociais têm se deparado com constantes desafios na última década, em especial no contexto da pandemia de Covid-19.

Conforme visto, estas duas mostras foram apenas algumas entre tantas oportunidades de visualização de materiais importantes para compreender nossa realidade, seja espiritual ou material, e que dificilmente estariam no circuito comercial de cinema. Os dois eventos, que não recorreram a exibições de horário fixo, ajudaram a manter a cultura cinematográfica e videográfica ativa em meio ao caos da crise sanitária. Acreditamos que sejam fenômenos que vieram para ficar, sem abrir mão das exibições presenciais. O importante é zelar pelo acesso a obras a um público cada vez maior.

\section{Referências}

Bassette, Fernanda. 2020. "Mãe perde guarda da filha de 12 anos após ritual de candomblé.” Época. Acesso a 31 de outubro 2021. https://oglobo.globo.com/epoca/mae-perde-guarda-da-filha-de12-anos-apos-ritual-de-candomble-24571523.

Cirino, Nathan Nascimento e Canuto, Kleyton Jorge. 2021. "Festivais de cinema pós-Covid-19: impactos e perspectivas." Significação: Revista de Cultura Audiovisual 48(56): 268-284. Acesso a 31 de outubro

2021. https://www.revistas.usp.br/significacao/article/view/176299.

Gshow. 2020. "Morre o ator Gésio Amadeu, aos 73 anos; relembre a carreira." Gshow. Acesso a 01 de dezembro de 2021. https://gshow.globo.com/Famosos/noticia/morre-o-ator-gesioamadeu-aos-73-anos-relembre-a-carreira.ghtml.

Madeiro, Carlos. 2021. "Mais miséria, mais fome. 2 milhões de famílias caíram na extrema pobreza durante o governo Bolsonaro." UOL Notícias. Acesso a 31 de outubro 2021. 
https://noticias.uol.com.br/reportagens-especiais/mais-miseriamais-fome/.

Marins, Thays e Peres, Edis Henrique. 2021. "Lideranças religiosas denunciam violência policial nas buscas por Lázaro em terreiros." Correio Brasiliense. Acesso a 31 de outubro 2021. https://www.correiobraziliense.com.br/cidadesdf/2021/06/4932387-em-buscas-por-lazaro-policiais-invademterreiros-entre-aguas-lindas-e-cocalzinho.html.

Miranda, Eduardo. 2020. "Terreiro de umbanda é incendiado na Região Metropolitana do Rio de Janeiro.” Brasil de Fato. Acesso a 31 de outubro 2021. https://www.brasildefato.com.br/2020/09/09/terreiro-deumbanda-e-incendiado-na-regiao-metropolitana-do-rio-dejaneiro.

Oliveira, Vinícius Andrade De e Alves, Álvaro Andrade. 2021. Mostra 2021: Joel Zito Araújo: uma década em vídeo 1987-1997. Belo Horizonte: Ponta de Areia. Acesso a 31 de outubro 2021. https://mostrajoelzitoaraujo.com.br/catalogo/.

Sobre. 2021. Festival Cine Terreiro. Acesso a 31 de outubro 2021. https://cineterreiro.com.br/sobre/.

\section{Filmografia}

A exceção e a regra [média metragem, digital]. Dir. Joel Zito Araújo. Tapiri Vídeo, Brasil, 1997. 31mins.

A negação do Brasil [longa metragem, digital]. Dir. Joel Zito Araújo. Casa de Criação, Brasil, 2001. 90mins.

As cores do divino [longa metragem, digital]. Dir. Victor Costa Lopes. Orla Filmes, Brasil, 2020. 78mins.

As filhas do vento [longa metragem, digital]. Dir. Joel Zito Araújo. S/Produtora, 2004. 85mins.

Afro-amazônicos e seus símbolos [curta metragem, digital]. Dir. Tainah Jorge. S/Produtora, 2016. $28 \mathrm{mins}$.

Alma negra da cidade [curta metragem, digital]. Dir. Joel Zito Araújo. Tapiri Vídeo, Brasil, 1991. 30mins. 
Almerinda, uma mulher de trinta [curta metragem, digital]. Dir. Joel Zito Araújo. Tapiri Vídeo, TV Viva, Brasil, 1991. 25mins.

Cinderelas, lobos e um príncipe encantado [longa metragem, digital]. Dir. Joel Zito Araújo. José Carlos de Alencar, Casa de Criação, Brasil, 2009. 108mins.

Doutor Gama [longa metragem, digital]. Dir. Jefferson De. Buda Filmes, Globo Filmes, Paranoid Filmes, Brasil, 2021. 82mins.

Eu, mulher negra [curta metragem, digital]. Dir. Joel Zito Araújo. Tapiri Vídeo, Brasil, 1994. 31mins.

Homens de rua [curta metragem, digital]. Dir. Joel Zito Araújo. Tapiri Vídeo, Brasil, 1991. 32mins.

Joãosinho da Goméa - O rei do candomblé [curta metragem, digital]. Dir. Janaina Oliveira Refem e Rodrigo Dutra. Dutra Filmes, Brasil, 2020. $15 \mathrm{mins}$.

Mãtãnãg, a encantada [curta-metragem, digital]. Dir. Shawara Maxakali e Charles Bicalho. Pajé Filmes, Brasil, 2019. 14mins.

Memórias Afro-Atlânticas [longa metragem, digital]. Dir. Gabriela Barreto. Couraça Criações Culturais, Brasil, 2019. 76mins.

Memórias de classe [média metragem, digital, digital]. Dir. Joel Zito Araújo. Tapiri Vídeo, Brasil, 1989. 40mins.

Meu amigo Fela [longa metragem]. Dir. Joel Zito Araújo. Joel Zito Araújo, Luiza Botelho Almeida, Casa de Criação de Cinema e Artes, Brasil, 2019. 94mins.

Nigiro: meu nome, minha ancestralidade [curta metragem, digital]. Dir. Assaggi Piá, Rodrigo Mends, Brasil, 2020. 12mins.

Nossos bravos [curta-metragem, digital]. Dir. Joel Zitto Araújo e Peter Overbeck. DIEESE - Departamento Intersindical de Estatísticas e Estudos socioeconômicos - Equipe de Educação Sindical/ Montevideo, Brasil, 1987. 31mins.

O atabaque na minha vida [curta-metragem, digital]. Dir. Jéssica Martins. Saravei! Produções, Brasil, 2019. 17mins.

O jardim fantástico [curta metragem, digital]. Dir. Fábio Baldo e Tico Dias. Filmes da Gruta, Lira Cinematográfica, Tabuleiro Filmes, Brasil, 2020. 20mins. 
O seu amor de volta (mesmo que ele não queira) [longa metragem, digital]. Dir. Bertrand Lira. Diego Benevides, Brasil, 2018. $82 \mathrm{mins}$.

Retrato em preto e branco [curta metragem, digital]. Dir. Joel Zito Araújo. Paulo Bueno, Bia Ribeiro - Companhia de vídeo, Brasil, 1992. 15 mins.

São Paulo abraça Mandela [curta metragem, digital]. Dir. Joel Zito Araújo. Tapiri Vídeo, Brasil, 1991. 30mins.

Terreiro de Cinema [curta metragem, digital]. Dir. Rodrigo Sena. Ori, Aboca Audiovisual, Brasil, 2021. 21mins. 